\title{
POR QUE ANALISAR A GESTÃO DAS INCUBADORAS DE EMPRESAS DE BASE TECNOLÓGICA SOB A ÓTICA DA RESOURCE-BASED VIEW?
}

\author{
Silvana Alves Silva* \\ silvana@adm.cefetmg.br
}

Adelaide Maria Coelho Baêta

adelaide.baeta@unifemm.edu.br

Janete Lara de Oliveira

janetelara@face.ufmg.br

*Universidade Federal de Minas Gerais

http://dx.doi.org/10.1590/1413-2311.03615.60897

Recebido em 15/12/2015

Aprovado em 23/09/2016

Disponibilizado em 31/01/2017

Avaliado pelo sistema "double blind review"

Revista Eletrônica de Administração

Editora-chefe: Aurora Zen

ISSN 1413-2311 (versão "on line")

Editada pela Escola de Administração da Universidade Federal do Rio Grande do Sul.

Periodicidade: Quadrimestral

Sistema requerido: Adobe Acrobat Reader

\section{RESUMO}

Este artigo aponta o campo da Resource-based View (RBV) como uma importante abordagem teórica para o entendimento da gestão das incubadoras de empresas de base tecnológica (IEBTs), tendo em vista que essas organizações lidam com uma série de recursos internos e externos, tangíveis e intangíveis, que, combinados, tornam viável o processo de inovação. Estudos teóricos e empíricos já realizados abordam, principalmente, aspectos relacionados aos resultados alcançados pelas empresas incubadas. Contudo, não se tem visto na literatura uma preocupação em compreender a organização interna das IEBTs, indo além de suas características e identificando como a gestão obtém e lida com os recursos necessários à concretização de seus objetivos. Partiu-se de uma revisão bibliográfica dos principais textos publicados desde o final da década de 1990 sobre a RBV a fim de se apropriar de suas contribuições para compreensão das organizações enquanto um conjunto de recursos e competências. Buscou-se, ainda, estudos publicados sobre as IEBTs para identificação dos principais recursos desenvolvidos e acessados por elas. Essa análise revela que as incubadoras são um conjunto amplo de recursos e, por isso, é importante que os gestores identifiquem, organizem, combinem e explorem recursos específicos que claramente geram vantagens competitivas. Por essa ótica, a diferença de desempenho observada nessas incubadoras é explicada pela maneira de lidar com os recursos. O enfoque nos recursos acessados e desenvolvidos pelas IEBTs apontou para a necessidade de uma análise específica a cerca das competências em lidar com esses recursos de forma a assegurar a sustentabilidade dessas organizações. 
Palavras-chave: Resource-based View; Incubadoras; Vantagens competitivas.

\title{
WHY ANALYZE THE MANAGEMENT OF THE INCUBATORS OF TECHNOLOGY-BASED COMPANIES FROM THE PERSPECTIVE OF RESOURCH-BASED VIEW?
}

\begin{abstract}
This article points out the Resource-based View (RBV) field as an important theoretical approach to understanding the management of incubators of technology-based companies (IEBTs), given that these organizations need to access a number of internal and external resources, tangible and intangible, which, combined, make the process of innovation feasible. Theoretical and empirical studies already address mainly issues related to the results achieved by incubated companies. However, a concern in understanding the internal organization of IEBTs cannot be seen in the literature, beyond their features and identifying how management collects and handles the resources needed to meet their goals. It started from a literature review of the main texts published since the late 1990s on the RBV to appropriate their contribution to the understanding of organizations as a set of resources and expertise. It sought to also published studies on IEBTs to identify the main features developed and accessed by them. This analysis reveals that the incubators are a wide range of resources and, therefore, it is important that managers identify, organize, combine and exploit specific features that clearly create competitive advantage. By this light, the performance difference observed in these incubators is explained by way of handling resources. The focus on resources accessed and developed by IEBTs pointed to the need for a specific analysis about the skills in handling these resources to ensure the sustainability of these organizations.
\end{abstract}

Keywords: Resource-based View; Incubators; Competitive advantages.

\section{¿POR QUÉ ANALIZAR LA GESTIÓN DE LAS INCUBADORAS DE EMPRESAS DE BASE TECNOLÓGICA DESDE LA PERSPECTIVA DE LA VISIÓN BASADA EN RECURSOS?}

\section{RESUMEN}

Este artículo señala el campo de la Resource-based View (RBV) como un enfoque teórico importante para la comprensión de la gestión de las incubadoras de empresas de base tecnológica (IEBTs), dado que estas organizaciones se ocupan de una amplia gama de recursos internos y externos, tangibles e intangibles que hacen posible el proceso de innovación. Los estudios teóricos y empíricos ya abordan principalmente temas relacionados con los resultados obtenidos por las empresas incubadas. Sin embargo, no es común ver en la literatura una preocupación con la comprensión de la organización interna de las IEBTs yendo más allá de sus características, para identificar cómo la administración recoge y maneja los recursos necesarios para cumplir con sus objetivos. Se realizó una revisión bibliográfica de los principales textos publicados desde finales de 1990 acerca de la RBV con el fin de entender su contribución en la comprensión de las organizaciones como un conjunto de recursos y capacidades. También fueron buscados estudios publicados sobre IEBTs para identificar los principales recursos desarrollados y a los que se accede con ellas. Este análisis revela que las incubadoras tienen una amplia gama de recursos importantes que los gerentes deben identificar, organizar, combinar y explotar para crear una clara ventaja competitiva. De esta manera, los diferentes desempeños observados en estas incubadoras se explican por 
medio del manejo de sus recursos. Los recursos a los que se tuvieron acceso y los que fueron desarrollados por las IEBTs señalan la necesidad de un análisis específico sobre las habilidades en el manejo de dichos recursos para asegurar la sostenibilidad de estas organizaciones.

Palabras clave: Resource-based View; Incubadoras; Ventajas competitivas.

\section{INTRODUÇÃO}

$\mathrm{O}$ sistema de incubação de empreendimentos foi iniciado em meados do século $\mathrm{XX}$ nos países desenvolvidos. No Brasil, as primeiras políticas públicas de apoio aos parques tecnológicos e às incubadoras de empresas foram lançadas na década de 1980. A Associação Nacional de Entidades Promotoras de Empreendimentos de Tecnologias Avançadas (Anprotec), criada em 1987 no Brasil, passou a representar não só os interesses das incubadoras de empresas e dos parques tecnológicos, mas de todo e qualquer empreendimento que utilizasse o processo de incubação para gerar inovação no País (SILVA, 2010b). A Anprotec, enquanto rede nacional, congrega uma multiplicidade de redes, em diferentes níveis, complementando-se umas às outras para tornar possível o desenvolvimento das organizações que compõem o sistema de incubação brasileiro (ALMEIDA, 2011).

Para Lalkaka (2003), incubadora é a denominação utilizada na definição do espaço institucional para apoiar a transformação de empresários potenciais em empresas crescentes e lucrativas. Nessas incubadoras, promovem-se oportunidades para o desenvolvimento tecnológico de processos produtivos e são oferecidos aos novos empreendedores não apenas espaço físico e serviços de escritório, mas, também, apoio administrativo, aconselhamento e consultoria gerencial e de marketing (BAÊTA, 1999).

As incubadoras de empresas estão vinculadas, na maioria das vezes, às universidades e às instituições de pesquisa e têm como finalidade primordial apoiar o desenvolvimento de ideias e a formação de empresas. Elas têm como papéis principais: facilitar a integração das empresas incubadas em redes relacionais, dar assistência técnica e gerencial e treinamentos para desenvolvimento dos novos negócios, além da tradicional disponibilização de infraestrutura de uso compartilhado e de recursos, entre outros, que ampliem a possibilidade de sobrevivência dos novos negócios (SERRA, RIBEIRO SERRA, PORTUGAL FERREIRA et al., 2011). Existem várias modalidades de incubadoras de empresas, sendo que as de base tecnológica - as IEBTs - constituem o foco deste estudo.

Para Baêta, Borges e Tremblay (2005, p. 77), IEBTs são: 
[...] organizações que abrigam empreendimentos nascentes, geralmente oriundos de pesquisa científica, cujo projeto implica o desenvolvimento e a comercialização de produtos ou serviços de base tecnológica. Tais organizações oferecem espaço e serviços subsidiados que favorecem o empresariamento e o desenvolvimento de produtos ou processos de alto conteúdo científico e tecnológico.

Para cumprir seus objetivos, as IEBTs desenvolvem uma série de recursos tangíveis e intangíveis, em interação com os agentes de inovação, quais sejam Governo, Academia e Empresas. Esses agentes compõem o chamado modelo Triple Helix, que foi desenvolvido para ampliar e suportar a interação entre tais agentes, visando à produção de novos conhecimentos, à inovação tecnológica e ao desenvolvimento econômico (ETZKOWITZ, 2009). O Brasil conta, ainda, com a participação de outras importantes entidades privadas e organizações, tais como, o Serviço Brasileiro de Apoio às Micro e Pequenas Empresas (Sebrae), as redes de inovação, as federações das indústrias, que, também, contribuem para essa interação. Os recursos desenvolvidos são de capital físico e financeiro (infraestrutura física, laboratórios, localização geográfica, recursos financeiros e outros), recursos de capital humano (trabalhadores, competências, experiências, network e outros), recursos de capital organizacional (planejamento, formas de coordenação), e recursos de capital relacional (network).

Estudos teóricos e empíricos estão sendo realizados sobre as IEBTs, abordando, principalmente, aspectos relacionados aos resultados alcançados pelas empresas incubadas em termos de empregos gerados, faturamento, patentes registradas, empresas graduadas, parcerias construídas, produtos colocados no mercado, entre outros. Contudo, não se tem visto na literatura uma preocupação em compreender a organização interna das IEBTs, indo além de suas características, e identificando como a gestão obtém e lida com os recursos necessários à concretização de seus objetivos. Este texto, que tem como foco a gestão dos recursos, visa dar uma contribuição teórica para preenchimento dessa lacuna.

O estudo da gestão das IEBTs é necessário para o desenvolvimento de conhecimentos que possam auxiliar na ampliação dos resultados alcançados por essas organizações. A isso, Zouain e Silveira (2006) acrescentam que os estudos dentro dessa perspectiva necessitam ser incrementados, considerando que essas incubadoras precisam se desenvolver de forma eficaz para que consigam acessar os recursos essenciais, os quais são disputados por um número cada vez maior de incubadoras.

Ainda nessa direção, o processo de criação e de legitimação de empresas de base tecnológica tem algumas particularidades, o que exige um estudo mais acurado sobre seu 
gerenciamento. Autores tais como Borges, Bernasconi, Filion (2003); Baêta, Borges e Tremblay (2005) corroboram essa afirmação. São várias as razões que dificultam esse processo: as empresas de base tecnológica fazem, em geral, parte de uma nova indústria e propõem ao mercado alguma inovação e, em muitos casos, o mercado não possui uma base de conhecimento sólida para o tipo de produto ou serviço que a nova empresa está lançando. $\mathrm{Na}$ maioria das vezes, esses empreendedores precisam criar um novo mercado. Essas empresas exigem, também, mais recursos a serem empregados no seu desenvolvimento inicial e na constante atualização tecnológica dos produtos e serviços. E, por fim, os empreendedores que constituem essas empresas caracterizam-se por serem mais bem qualificados em termos de formação, mas não, necessariamente, experientes em termos gerenciais.

Por fim, em um estudo comparativo sobre incubadoras de diferentes países, Soetanto e Geenhuizen (2007) constataram um aumento do investimento público e privado em IEBTs nos últimos tempos, o que para eles amplia a necessidade da construção de conhecimentos a cerca dos fatores que determinam o seu desempenho, inclusive para apoiar as decisões políticas sobre essas incubadoras.

A literatura existente sobre incubadoras é recente, conforme é salientado por Phan, Siegel e Wright (2005), e cada trabalho de pesquisa realizado lança luz sobre uma dimensão ainda inexplorada do tema. Baêta (1999) iniciou a pesquisa sobre o tema no Brasil, tendo como contexto de análise o ambiente cultural e empresarial brasileiro. Relevantes questões práticas sobre as IEBTs foram apresentadas pela autora, embasando os estudos brasileiros posteriores sobre o tema. Soetanto e Geenhuizen (2007) apontam para uma falta de dados empíricos sobre as incubadoras pequenas e de pouco sucesso, uma vez que os relatórios tendem a publicar apenas as histórias de sucesso.

Clarysse, Wright, Lockett et al. (2005), ao analisarem algumas organizações que apoiam o desenvolvimento de empresas de base tecnológica da Europa, deram importante contribuição ao identificar os recursos e competências relacionados a finanças, organização, recursos humanos, tecnologia, rede e infraestrutura desenvolvidos por essas organizações. Etzkowitz, H; Mello, J; Almeida, M. (2005) explicam que o movimento de incubação surgiu na transição de projetos de alta tecnologia do antigo regime militar, mas que o foco original de alta tecnologia das incubadoras foi reconfigurado, passando para um conjunto mais amplo de propósitos dos atores que compõem a Triple Helix.

Zouain e Silveira (2006) ressaltam três aspectos que afetam o modelo de gestão das incubadoras e ampliam e qualificam os recursos acessados: cada incubadora é desenvolvida 
para alcançar objetivos específicos que dependem, entre outras coisas, da instituição à qual está vinculada e da região onde está estabelecida; o estágio de desenvolvimento da incubadora; e a existência de múltiplos stakeholders. Soetanto e Geenhuizen (2007) corroboram essa constatação de que as versões modernas de incubadoras podem ser vistas como uma manifestação do modelo da Triple Helix, como coletores de recursos e como agentes intermediários da inovação.

Serra, Ribeiro Serra, Portugal Ferreira et al. (2011) examinam o efeito das redes relacionais, geradas durante o processo de incubação, e os fatores que influenciam a efetividade e sustentabilidade das incubadoras. Silva (2010a; 2010b) destaca que os papeis sociais mais relevantes exercidos pelas IEBTs são a geração de novas empresas de base tecnológica, a geração de emprego e renda e a transferência de novas tecnologias para as empresas. Almeida, Borin, Álvarez et al. (2011) sintetizam o contexto social e político no qual houve o surgimento das incubadoras no Brasil e destacam a importância da formação de redes estaduais e regionais, encorajadas pela ANPROTEC, para a reunião de incubadoras locais, troca de experiências e busca de apoio em nível regional.

A Anprotec, o MCTI e o Sebrae têm se preocupado em publicar relatórios, apresentando os resultados já alcançados pelas incubadoras (ANPROTEC, 2012). Pastre e Vedovatto (2014) dedicaram-se ao estudo das fontes de recursos financeiros das incubadoras, concluindo que as incubadoras ampliarão o volume e a variedade de suas receitas financeiras por meio da captação de novos recursos e da geração de novas fontes de renda, seja pela oferta de novos serviços ou pela conquista de novos clientes e parceiros. Mas as autoras ressaltam que não é importante apenas ampliar as receitas, é necessário também desenvolver competências gerenciais para otimizar sua utilização.

Rezende (2015), ao pesquisar dois programas de incubação no Estado da Flórida, Estados Unidos, conclui que as incubadoras são importantes mecanismos de transformação do conhecimento, gerado nos departamentos universitários, em novos produtos e serviços, proporcionando competitividade à economia de um modo geral.

Recentemente, no Brasil, a Anprotec e o Sebrae construíram um modelo de atuação para as incubadoras, o Centro de Referência para Apoio a Novos Empreendimentos (CERNE), que se encontra em vigor. Essas instituições entendem que as incubadoras brasileiras precisam ampliar quantitativa e qualitativamente seus resultados, de forma a alcançar um percentual mais expressivo da população, e, para isso, consideram ser essencial 
que implantem processos que deem conta da complexidade do contexto econômico e social (GARCIA, BIZZOTTO, PIRES et al. 2015).

As diferentes dimensões exploradas na literatura apresentada esclarecem em torno de quais questões este campo de estudo tem sido pesquisado, nos últimos dez anos, revelando, de forma notória, a lacuna existente, ou seja, a ausência de conhecimento sobre a gestão específica dos recursos das IEBTs e em que ela se difere da gestão das outras organizações. Essa lacuna motiva o estudo da gestão das IEBTs a partir da ótica da RBV.

Este artigo aponta o campo da Resource-based View (RBV) como um importante recurso teórico para o entendimento da gestão das IEBTs, tendo em vista que essas organizações necessitam acessar uma série de recursos internos e externos, tangíveis e intangíveis, que, combinados tornam viável o processo de inovação. A RBV, como será apresentada na próxima seção, tem auxiliado na compreensão do papel que os recursos desempenham na geração de fontes de vantagens competitivas para as organizações e, por conseguinte, explicado o porquê as organizações obtêm resultados diferentes conforme suas habilidades em arranjar, combinar e explorar seus recursos.

Este estudo é composto por esta introdução, duas seções e pelas considerações finais. A primeira seção apresenta uma visão geral sobre a RBV. A seção seguinte traz uma discussão sobre os recursos desenvolvidos pelas IEBTs, identificados na literatura, e sua interpretação a partir do campo teórico da RBV. As considerações finais contemplam a análise dos pontos chaves discutidos neste artigo e algumas indicações de novos estudos para o avanço deste debate.

\section{1 - UM BREVE PANORAMA DA RESOURCE-BASED VIEW}

A Resource-based View (RBV) é a contribuição mais relevante, especialmente a partir da década de 1990, para os estudos no campo das estratégias organizacionais (RAMOSRODRIGUES e RUIZ-NAVARRO, 2004). Em essência, a RBV é uma lente teórica que se desenvolveu a partir das perspectivas econômicas de Penrose (1959), das quais se vislumbrou a possibilidade de distinção de uma empresa como algo determinado pela heterogeneidade dos produtos e serviços disponíveis ou potencialmente disponíveis a partir de seus recursos. Sob essa perspectiva, uma organização é um conjunto amplo de recursos.

Os dois textos mais influentes dessa abordagem foram os escritos por Wernerfelt (1984) e Barney (1991). Enquanto Wernerfelt foi o pioneiro da visão baseada em recursos da empresa, Barney avançou ao desenvolver um modelo para identificar as características dos 
recursos estratégicos e, portanto, para a definição daqueles recursos que se constituiriam em uma fonte de vantagem competitiva (RAMOS-RODRIGUES e RUIZ-NAVARRO, 2004).

Especificamente no final da década de 1990, os estudos mais referenciados no campo da estratégia tinham estrita relação com a RBV: Penrose (1959), Nelson e Winter (1982), Lippman e Rumelt (1982), Teece (1982), Wernerfelt (1984), Rumelt (1984), Dierickx e Cool (1989), Prahalad e Hamel (1990), Cohen e Levinthal (1990), Barney (1991), Rumelt (1991) e Peteraf (1993). Todas essas abordagens convergem para o entendimento de que as organizações são compostas por um conjunto específico de atributos e recursos, como é referenciado na teoria de rotinas corporativas (Nelson e Winter) e na RBV, por um conjunto de competências e habilidades.

Penrose (1959) enfatiza que, muito além de uma entidade administrativa, a organização constitui-se em um conjunto de recursos produtivos, cuja disposição entre diversos usos e por meio do tempo é determinada por decisões administrativas. A RBV afirma que os recursos específicos (ou internos) da organização são aqueles de importância determinante para estabelecer a vantagem competitiva, por possuírem natureza e características únicas e não poderem ser livremente comprados e vendidos no mercado. Essa visão indica como é possível alcançar vantagem competitiva por meio da perspectiva dos recursos

Dierickx e Cool (1989) destacam-se por focarem precisamente aqueles tipos de recursos e capacidades que são de interesse central para a RBV: os ativos não negociáveis desenvolvidos e acumulados dentro da empresa. Tais ativos tendem a desafiar a imitação, porque eles têm uma dimensão tácita forte, são socialmente complexos e nascem da habilidade organizacional e do aprendizado corporativo. Os ativos dessa natureza são, por exemplo, imóveis, porque não são facilmente transferíveis para outras organizações e, portanto, vinculados diretamente à empresa. A imobilidade ou a imperfeita mobilidade constituem um fator relevante para obter-se vantagem competitiva sustentável.

Wernerfelt (1984) foi quem inicialmente teorizou a RBV para o campo da estratégia, apresentando a visão da organização como um agrupamento de recursos que permitem avaliar suas forças e fraquezas. Embora as cinco forças competitivas de Porter (1986) tenham sido originalmente utilizadas como ferramentas para a análise de produtos, Wernerfelt percebeu nelas uma possibilidade para a análise dos recursos. Essa perspectiva possibilita às organizações a elaboração de opções estratégicas diferentes, envolvendo, por exemplo, a 
busca pelo equilíbrio entre a exploração dos recursos existentes e o desenvolvimento de novos.

Peteraf (1993) sugere que os recursos e as competências que podem gerar vantagens competitivas sustentáveis devem apresentar as quatro condições que são apresentadas no Quadro 1.

Quadro 1: Condições essenciais para a geração de vantagens competitivas sustentáveis

\begin{tabular}{|c|l|}
\hline $\begin{array}{c}\text { Condições essenciais para a } \\
\text { geração de vantagens } \\
\text { competitivas }\end{array}$ & \multicolumn{1}{c|}{ Descrição } \\
\hline Heterogeneidade & $\begin{array}{l}\text { Em termos de seus recursos e competências, as organizações devem ser, fundamentalmente, } \\
\text { heterogêneas. }\end{array}$ \\
\hline $\begin{array}{c}\text { Imitabilidade e substitutibilidade } \\
\text { imperfeitas (limites ex-post) }\end{array}$ & $\begin{array}{l}\text { As organizações devem preservar seus recursos valiosos por meio das condições de } \\
\text { imperfeitas imitabilidade e substitutibilidade, estabelecendo limites ex-post à concorrência. } \\
\text { Com heterogeneidade, mas sem limites ex-post, as organizações terão diferenças facilmente } \\
\text { imitáveis. }\end{array}$ \\
\hline Imobilidade & $\begin{array}{l}\text { Os recursos devem ser perfeitamente imóveis, ou seja, não negociáveis para assumirem esta } \\
\text { condição. Esses recursos são idiossincráticos, na medida em que eles não têm outra } \\
\text { utilização fora da empresa. }\end{array}$ \\
\hline Limites ex-ante & $\begin{array}{l}\text { Esta condição refere-se à aquisição ou desenvolvimento por parte da empresa de recursos } \\
\text { que virão a ser raros ou superiores, por possuir informações privilegiadas acerca das } \\
\text { condições do mercado. }\end{array}$ \\
\hline \multicolumn{1}{|c|}{ Fonte: Peteraf (1993) } \\
\hline
\end{tabular}

Fonte: Peteraf (1993)

O modelo de Peteraf (1993) destaca a importância de cada uma dessas condições e, em particular, explica o papel que cada uma delas desempenha na criação e manutenção da lucratividade. No entanto, essas quatro condições são relacionáveis e não interdependentes. É importante reconhecer, também, que a produtividade superior dos recursos depende da natureza do seu trabalho e da habilidade com que uma estratégia, baseada na superioridade dos recursos, é implementada.

A grande contribuição do modelo baseado em recursos, identificada por Peteraf (1993), é que ele explica as diferenças duradouras na rentabilidade das empresas, que não podem ser atribuídas às diferenças nas condições da indústria. A autora cita estudos que evidenciam que tais diferenças não estão bem explicadas pela participação na indústria (Schmalensee, 1985; Mueller, 1986; Wernerfelt e Montgomery, 1988; Hansen e Wernerfelt, 1989; Rumelt, 1991), mas se explicam pelos efeitos internos das empresas (Mueller, 1986; Hansen e Wernerfelt, 1989; Rumelt, 1991).

Essas ideias e esses conceitos foram essenciais para o início da RBV e para sua evolução. Embora vários conceitos utilizados na RBV tenham vindo de autores diferentes, essa escola deve sua formalização teórica a Barney (Mintzberg, Ahlstrand, Lampel, 2000), que atrelou a essa teoria o conceito de vantagem competitiva. 
O tradicional modelo SWOT (Strengths, Weakness, Opportunities, Threats - ou Forças, Fraquezas, Oportunidades, Ameaças) sugere que uma organização está apta a melhorar seu desempenho somente quando suas estratégias exploram oportunidades ou neutralizam ameaças. Barney (1991) complementa essa perspectiva ao afirmar que os atributos de uma organização devem ter outras características que os qualifiquem como fontes de vantagem competitiva.

Barney (1991) investigou os recursos utilizados pela organização sob a ótica das questões de valor, de raridade, de imitabilidade e da organização dos recursos para a sustentabilidade da vantagem competitiva. Nesse sentido, as empresas obtêm vantagem competitiva sustentável ao implementar estratégias que exploram suas forças internas, respondendo às oportunidades do ambiente, enquanto neutralizam ameaças externas e evitam fraquezas internas.

$\mathrm{Na}$ visão desse autor, alguns pesquisadores têm se concentrado em isolar as oportunidades e ameaças das organizações (Porter, 1986, 1989), outros em descrever seus pontos fortes e fracos (Penrose, 1959; Stinchcombe, 1965; Hofer e Schendel, 1978), outros, ainda, em analisar como esses pontos são combinados na escolha das estratégias. Observa-se que os estudos que priorizam a análise externa dão pouca ou nenhuma ênfase ao impacto dos atributos idiossincráticos das organizações em relação à sua posição competitiva. Dentro dessa perspectiva, a abordagem da Visão da Organização Industrial, liderada por Porter, considera que as organizações pertencentes a uma mesma Indústria são homogêneas, não fazendo sentido, por isso, o estudo de seu ambiente interno para compreensão das diferenças das práticas competitivas organizacionais. Barney (1991) não questiona a importância da análise do impacto do ambiente externo sobre o desempenho das organizações, mas sim a eliminação da heterogeneidade e da inacessibilidade (ou imobilidade) dos recursos das organizações.

A RBV vem ampliar essa perspectiva ao examinar a ligação entre as características internas das organizações e o seu desempenho e levanta duas hipóteses alternativas. A primeira é que as organizações que fazem parte de uma indústria ou grupo podem ser heterogêneas em relação aos recursos estratégicos que controlam. A segunda é que esses recursos podem não estar perfeitamente acessíveis para todas as organizações, o que torna as organizações diferentes por mais tempo. O modelo baseado em recursos examina as implicações dessas duas hipóteses para a análise das fontes de vantagem competitiva sustentável. 
Inicialmente, Barney (1991) buscou definição para três conceitos: recursos, vantagem competitiva e vantagem competitiva sustentável. Os recursos de uma organização são compreendidos como todos os ativos, capacidades, processos organizacionais, atributos organizacionais, informação, conhecimento e outros, controlados por uma organização, que permitem que ela conceba e implemente estratégias que aumentem sua eficiência e eficácia (DAFT, 1983).

Uma organização tem vantagem competitiva quando ela está implementando uma estratégia de criação de valor impossível de ser praticada simultaneamente por outro competidor atual ou potencial. Seguindo essa ideia, uma organização tem vantagem competitiva sustentável quando está implementando uma estratégia de criação de valor impossível de ser praticada simultaneamente por outro competidor atual ou potencial e quando as outras organizações são incapazes de duplicarem os benefícios de sua estratégia (BARNEY, 1991).

Tendo sido definidos esses conceitos, Barney retoma ao conceito de recursos, associando-o aos conceitos de vantagem competitiva e vantagem competitiva sustentável, já que o conceito de recursos tem sido definido e categorizado de maneira distinta por alguns autores, exigindo seu maior aprofundamento. Uma possível classificação para os recursos de uma organização pode basear-se nas seguintes categorias, conforme cita Barney (1991): recursos de capital físico (Williamson, 1975), recursos de capital humano (Becker, 1964) e recursos de capital organizacional (Tomer, 1987).

Os recursos de capital físico incluem a tecnologia física utilizada na organização, tais como sua planta e equipamentos, a localização geográfica e seu acesso às matérias primas. Os recursos de capital humano incluem treinamento, experiência, julgamento na tomada de decisão, inteligência, relacionamento e perspicácia dos gestores e dos demais profissionais. Por fim, os recursos de capital organizacional incluem uma estrutura formal de relatórios, planejamento formal e informal, controle e sistemas de coordenação, bem como relações informais entre grupos dentro de uma organização e entre uma organização e seu ambiente. Barney quer mostrar com essa classificação a existência de não somente recursos tangíveis, mas, também, de recursos intangíveis dentro das organizações.

Penrose (1959) já havia considerado em suas análises uma perspectiva mais associada à intangibilidade dos recursos das organizações, ampliando seus conceitos para além dos recursos físicos e tangíveis, ou seja, considerando também recursos, tais como, as características e habilidades dos técnicos e gestores que estão a serviço da organização. É 
possível afirmar também que os recursos intangíveis são bens que se encontram profundamente enraizados na história da organização, que se acumularam com o passar do tempo como, por exemplo, conhecimentos e confiança recíproca entre colaboradores e ideias.

Collins (1994) reforça que a vantagem competitiva sustentável é obtida apenas por meio dos recursos intangíveis, uma vez que os recursos tangíveis, por sua natureza, podem ser facilmente identificados e copiados. Wernerfelt (1984) ressalta que recursos são os ativos tangíveis e intangíveis vinculados à organização de forma quase permanente, tais como marca, conhecimento e tecnologia, capacidades e habilidades dos empregados, contratos de negócio, capital, lealdade dos clientes, experiência da equipe, gestão profissional, dentre outros, capazes de trazerem para a organização altos retornos, por longos períodos de tempo.

A vantagem competitiva sustentável, para Hall (1992), resulta da posse de capacidades relevantes e diferenciais. Desse modo, as organizações obtêm vantagem competitiva sustentável quando, consistentemente, entregam produtos ou serviços que passam pelo crivo da maioria dos consumidores, ou seja, que comunicam algum valor a eles, que pode ser o preço, a qualidade, o padrão estético, a funcionalidade ou a imagem de um produto ou serviço. O diferencial apresentado por esses produtos ou serviços tem atributos relacionados aos recursos intangíveis da organização, tais como conhecimentos, habilidades, experiência da equipe, reputação, reserva de mercado, network, dentre outros.

Penrose (1959), Collins (1994), Wernerfelt (1984) e Hall (1992) sinalizaram a presença de atributos inerentes aos recursos intangíveis que podem proporcionar vantagens competitivas às organizações, muito mais que os recursos tangíveis. É importante, por essa razão, entender as condições em que esses recursos podem ser fonte de vantagem competitiva sustentável para uma organização e conduzi-la a um constante crescimento, aspecto que constitui o maior campo de pesquisa da RBV. As definições apresentadas, até então, sobre recursos e vantagens competitivas ajudam a compreender o impacto da heterogeneidade e da imobilidade (inacessibilidade) da vantagem competitiva sustentável.

Barney (1991) enfatiza a relevância de se construir um modelo teórico, tendo como referência as duas hipóteses levantadas acerca da heterogeneidade e a inacessibilidade dos recursos. Para que as organizações gerem vantagem competitiva sustentável, os recursos das organizações devem ter quatro atributos, a saber: serem valiosos, no sentido de que eles exploram oportunidades e neutralizam ameaças no ambiente organizacional; serem raros entre os competidores atuais e potenciais; serem inimitáveis; e não serem estrategicamente equivalentes aos substitutos, que são valiosos, mas não raros ou totalmente inimitáveis. Esses 
atributos são indicadores empíricos para a identificação de potenciais recursos organizacionais (ou ativos estratégicos de uma organização) que geram vantagem competitiva sustentável. Nos parágrafos seguintes, cada um desses atributos será analisado.

Os recursos são valiosos quando permitem à organização conceber ou implementar estratégias que aumentam sua eficiência e efetividade. A afirmação de que os atributos organizacionais devem ser valiosos para serem considerados recursos (e possíveis fontes de vantagem competitiva sustentável) aponta para uma importante complementaridade entre os modelos ambientais de vantagem competitiva e o baseado em recursos. Conforme esclarece Barney (1991), enquanto os modelos de análise ambiental ajudam a isolar aqueles atributos das empresas que exploram oportunidades ou neutralizam ameaças e, desse modo, especificam quais atributos organizacionais podem ser considerados como recursos, o modelo baseado em recursos sugere quais características adicionais esses recursos devem possuir para gerarem vantagem competitiva sustentável.

Os recursos valiosos são importantes, mesmo os não raros, pois eles podem garantir a sobrevivência da organização quando são explorados para criarem paridade competitiva em um setor industrial. Sob condições de paridade competitiva, embora nenhuma organização obtenha vantagem competitiva, é possível aumentar a probabilidade de sobrevivência econômica de uma organização (BARNEY, 1991).

Os recursos valiosos ou raros somente poderão ser fonte de vantagem competitiva sustentável se as organizações que não os detêm enfretam uma desvantagem de custo para obtê-los ou desenvolvê-los, comparadas às organizações que já os possuem. O quanto a raridade tem o potencial de gerar vantagem competitiva sustentável é uma questão difícil de ser respondida, mas é fácil perceber que, se um recurso de uma organização é único dentre as demais potencialmente competidoras, ele terá capacidade também única de trazer diferencial e vantagem competitiva, salienta Barney (1991).

Os recursos organizacionais devem ser valiosos e raros para serem fontes de vantagem competitiva, mas esses recursos somente podem ser fonte de vantagem competitiva sustentável se as organizações que não os possuem não puderem obtê-los, por serem imperfeitamente imitáveis ou copiáveis. As razões que levam os recursos a assumirem tal condição são: a habilidade de uma organização obter um recurso é dependente de condições históricas únicas; a ligação entre os recursos possuídos por uma organização e uma vantagem competitiva sustentável de uma organização é causalmente ambígua; ou a transformação de recurso em vantagem organizacional é socialmente complexa. 
Barney (1991) ressalta que a maioria dos modelos ambientais de vantagem competitiva organizacional, além da homogeneidade dos recursos e mobilidade (acessibilidade), explica que o desempenho das organizações pode ser alcançado independentemente de sua história particular e de outros atributos idiossincráticos (SCHERER, 1980; PORTER, 1981). Pesquisadores dessa linha raramente argumentam que as organizações não variam em termos de suas histórias únicas, mas sim que essas histórias únicas não são relevantes para entender o desempenho organizacional (PORTER, 1986).

No entanto, a RBV afirma que as organizações são intrinsecamente entidades históricas e sociais, e que sua habilidade para adquirirem e explorarem alguns recursos depende de seu lugar no tempo e no espaço. Isso quer dizer que as condições específicas de cada organização e a maneira adotada por ela para lidar com problemas e tomar decisões, por exemplo, é que fazem com que seus recursos não sejam perfeitamente imitáveis. Portanto, o desempenho de uma organização não depende simplesmente de uma estrutura industrial dentro da qual uma organização encontra-se em um ponto particular no tempo, mas também do caminho que ela segue através da história para chegar onde ela está. Se uma organização obtém recursos valiosos e raros por causa de seu caminho singular histórico, ela será capaz de explorar esses recursos na implementação de estratégias de criação de valor, que não podem ser duplicadas por outras organizações.

Na visão de Barney (1991), a ambiguidade causal existe quando o elo entre os recursos controlados e a vantagem competitiva sustentável de uma organização não é muito bem compreendido pelos concorrentes. É difícil para as organizações que estão tentando duplicar as estratégias de sucesso, por meio da imitação dos recursos, saber exatamente quais recursos devem ser imitados. Por outro lado, quando uma organização que sustenta uma vantagem competitiva consegue compreender o elo entre os recursos controlados por outra organização e suas vantagens, elas podem aprender sobre aquele elo e adquirirem os recursos necessários (assumindo que eles não são imperfeitamente imitáveis) para implementarem as estratégias necessárias para fazer face a esse concorrente. Em tal contexto, as vantagens competitivas da organização não são sustentáveis, porque elas podem ser duplicadas e elimina-se, com isso, a ambiguidade causal e a imperfeita imitabilidade.

Os recursos controlados por uma organização são complexos e interdependentes. Embora os gestores possuam hipóteses sobre quais recursos geram vantagens para as organizações, não é possível testar rigorosamente essas hipóteses. Enquanto numerosas explicações plausíveis das fontes de vantagem competitiva sustentável existem dentro de uma 
organização, a ligação entre os recursos controlados por uma organização e a vantagem competitiva sustentável permanece um tanto ambígua e, portanto, continua incerto qual recurso de uma organização deve ser imitado.

A última razão pela qual os recursos de uma organização são imperfeitamente imitáveis é que eles são um fenômeno social muito complexo, indo além da habilidade das organizações de, sistematicamente, gerenciá-los e influenciá-los. Barney (1991) explica que quando as vantagens competitivas são baseadas em um fenômeno social complexo, a possibilidade para outras organizações imitarem esses recursos fica significativamente restrita. Alguns exemplos dessa complexidade social podem ser encontrados na cultura organizacional, com seus atributos próprios, na qualidade da relação entre gerentes e subordinados, ou na reputação da organização diante de fornecedores e clientes. Na medida em que os recursos organizacionais socialmente complexos não estão sujeitos ao gerenciamento direto, esses recursos são imperfeitamente imitáveis.

Por fim, são exemplos de recursos imperfeitamente imitáveis os seguintes recursos intangíveis: reputação, network e liderança de mercado. Tais recursos são decorrentes de aprendizagem produtiva ou, conforme explica Barney (1991), são decorrentes de ambiguidade causal, ou seja, são recursos que não são bem compreendidos por seus concorrentes por causa da complexidade da relação entre os recursos e a sustentação da vantagem competitiva. Esses recursos proporcionam limites à competição ex-post, ou seja, há dificuldade ou impossibilidade de os competidores imitá-los, o que permite a sustentabilidade dos ganhos pelas organizações (PENROSE, 1959).

Barney (1991) estabelece como última exigência para que o recurso de uma organização seja considerado fonte de vantagem competitiva sustentável, além de ter valor, ser raro e de difícil imitação, que ele não seja estrategicamente equivalente ao de outras organizações. Dois recursos organizacionais valiosos (ou dois pacotes de recursos organizacionais) são estrategicamente equivalentes quando cada um pode ser explorado separadamente para implementar as mesmas estratégias. Tal condição não existe apenas quando os recursos são similares, pois recursos muito diferentes podem, também, ser estrategicamente substitutos.

Embora não seja possível para uma organização imitar de forma exatamente igual os recursos de outras organizações, ela pode ser capaz de substituir o recurso almejado por um recurso similar, que permita a ela conceber e implementar as mesmas estratégias. Seguindo essa lógica, diferentes equipes de trabalho, por exemplo, podem ser estrategicamente 
equivalentes. Uma equipe de trabalho pode não ser uma fonte de vantagem competitiva sustentável, apesar de uma equipe de trabalho de uma organização em particular, em especial uma equipe gerencial, ser valiosa, rara e imperfeitamente imitável. E, ainda, se um grande número de organizações concorrentes tem um sistema de planejamento formal que gera uma visão comum (ou se um planejamento formal é altamente imitável), então essas organizações não terão uma vantagem competitiva sustentável, apesar de os recursos organizacionais, como os construídos por uma liderança do tipo carismática, serem provavelmente raros e imperfeitamente imitáveis.

Enfim, para que o recurso de uma organização seja considerado fonte de vantagem competitiva sustentável, ele precisa, além de ter valor, ser raro e de difícil imitação; não pode ser estrategicamente equivalente ao de outras organizações.

De acordo com o modelo construido por Barney (1991), existe uma relação entre a heterogeneidade e a imobilidade; entre o valor, a raridade, a imitabilidade e a substitutibilidade e a vantagem competitiva sustentável. Para que os recursos possam ser considerados fontes de vantagens competitivas, os mesmos devem seguir os pressupostos de heterogeneidade e imobilidade, entendendo por heterogeneidade os recursos que são considerados diferentes e de difícil aquisição no mercado, e imobilidade como a dificuldade de transferir esses recursos para outras organizações. A vantagem competitiva de uma organização é derivada dos recursos distintos que ela possui. Um recurso raro e valioso e de cujo valor a organização possa se apropriar é uma fonte de vantagem competitiva para essa organização. Porém, ela se torna sustentável se tal recurso for também inimitável, insubstituível e de baixa mobilidade.

Para analisar se os recursos são fontes de vantagem competitiva sustentável, Barney (1991) sugere a aplicação do esquema, apresentado na Figura 1. Contudo, a exposição feita nesta seção sobre a RBV especifica tão somente as condições teóricas sob as quais a vantagem competitiva deve existir. Questões empíricas específicas precisam ser endereçadas antes de poder ser entendida, com maior clareza, a relação entre um recurso particular e a vantagem competitiva sustentável.

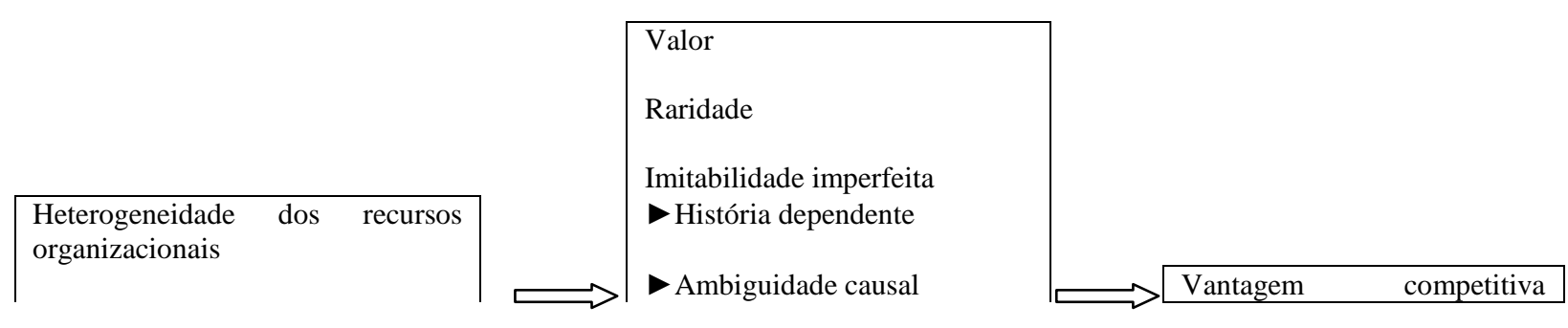

REAd | Porto Alegre - Edição 85 - № 3 - Setembro / Dezembro 2016 - p. 462 - 493 
Figura 1: A relação entre a heterogeneidade e a imobilidade do recurso, valor, raridade, imitabilidade perfeita e substitutibilidade e a vantagem competitiva sustentável

Fonte: Adaptado de Barney (1991)

\section{2 - OS RECURSOS DESENVOLVIDOS PELAS IEBTS À LUZ DO CAMPO TEÓRICO DA RESOURCE-BASED VIEW}

Uma incubadora é uma entidade que tem por objetivo oferecer suporte aos empreendedores residentes para que esses desenvolvam ideias inovadoras e as transformem em empreendimentos de sucesso (SILVA, 2010b). Soetanto e Geenhuizen (2007) definem incubadoras, mais precisamente as IEBTs, como organizações que visam acelerar o desenvolvimento de empresas de alta tecnologia, fornecendo uma matriz de recursos e de serviços.

O que se observa é que as incubadoras disponibilizam infraestrutura física e serviços administrativos compartilhados, além de espaço físico individual, laboratórios e equipamentos, por meio de parcerias com centros de pesquisa, universidades, agências de transferência de tecnologia ou mesmo através do leasing de equipamentos. O suporte gerencial é relevante, porque os empreendedores necessitam de conhecimentos administrativo, financeiro e de marketing para desenvolverem seus produtos e comercializálos. O suporte técnico, por sua vez, auxilia as empresas incubadas no desenvolvimento de protótipos, na transferência de tecnologia e na difusão do conhecimento tecnológico. A assistência jurídica diz respeito, sobretudo, à garantia da propriedade intelectual, à formalização de contratos de pesquisa e à transferência de tecnologias. Por fim, as incubadoras proporcionam o acesso às redes de trabalho e aos recursos financeiros, essenciais ao estágio inicial de uma empresa e ao seu desenvolvimento.

As IEBTs apoiam empresas voltadas para setores tecnologicamente dinâmicos e que têm na inovação ou no aprimoramento tecnológico (de produto ou de processo) o diferencial do seu negócio, ou seja, são diferentes, porque não incubam atividades precárias em conhecimento (NBIA) ${ }^{1}$. Tendo por base o conhecimento, geralmente, estão vinculadas a centros avançados de pesquisa e de desenvolvimento tecnológico. A criação desse tipo de incubadora tem se mostrado um processo eficiente para a transferência de tecnologia e para a

\footnotetext{
${ }^{1}$ Publicado no portal da NBIA, na seção Business Incubation FAQs: www.nbia.org.
} 
cooperação institucional entre universidade e empresa, exercendo papel decisivo na interface entre ciência e tecnologia e o setor empresarial.

Ao oferecer suporte ao empreendedor residente, a incubadora possibilita que seu empreendimento tenha mais chances de ser bem sucedido. Além de condições favoráveis de infraestrutura e capacitação dos empreendedores, as empresas - pelo fato de estarem em um espaço onde há vários empreendimentos inovadores do mesmo porte - contam com numerosas conexões, que favorecem o crescimento do negócio e o acesso ao mercado. As incubadoras auxiliam na redução de custos e riscos do processo de inovação, pois permitem o acesso a laboratórios e a equipamentos que, sem o auxílio da incubadora, exigiria elevados investimentos. Além disso, amenizam os altos custos exigidos para o ingresso de produtos em novos mercados (ANPROTEC) $)^{2}$.

Independente da natureza do seu vínculo - se às instituições públicas, privadas ou híbridas -, as incubadoras necessitam criar mecanismos de aprendizado, cooperação, relacionamentos e parcerias, possibilitados por meio de sua interação com as três instituições sociais - Governo, Academia e Empresas -, de acordo com o modelo da Triple Helix (Etzkowitz, 2009) e com outros tipos de organizações privadas, tais como o Sebrae. A interação com esses agentes possibilita às incubadoras o acesso aos recursos empregados no desenvolvimento dos projetos e de empresas incubados, mas, para isso, é necessário clareza na identificação dos recursos adequados para cumprimento de seus objetivos.

Como o presente estudo caracteriza-se por ser predominantemente teórico, a análise dos recursos acessados e desenvolvidos pelas IEBTs será feita a partir de alguns estudos publicados, principalmente a partir de 2005 , e cujos pesquisadores tenham explicitado o papel desempenhado pelos recursos nos resultados alcançados pelas incubadoras estudadas.

Recorrendo aos estudos de Clarysse, Wright, Lockettet et al. (2005) e de Brush, Green e Hart (2001), que são bastante próximos da análise proposta neste artigo para as IEBTs, elaborou-se uma síntese da classificação dos recursos citados nesses estudos, conforme pode ser visto no Quadro 2. Os recursos neles identificados são relevantes para a geração de vantagens competitivas nas IEBTs e, por isso, se ainda não desenvolvidos internamente por essas organizações, deveriam ser considerados dada a sua relevância para o alcance dessas vantagens.

Quadro 2: Recursos desenvolvidos pelas IEBTs

\footnotetext{
${ }^{2}$ Publicado no portal da Anprotec, na seção Perguntas Frequentes: www.anprotec.org.br.
} 


\begin{tabular}{|c|c|}
\hline Grupo & Exemplos \\
\hline Organizacionais & 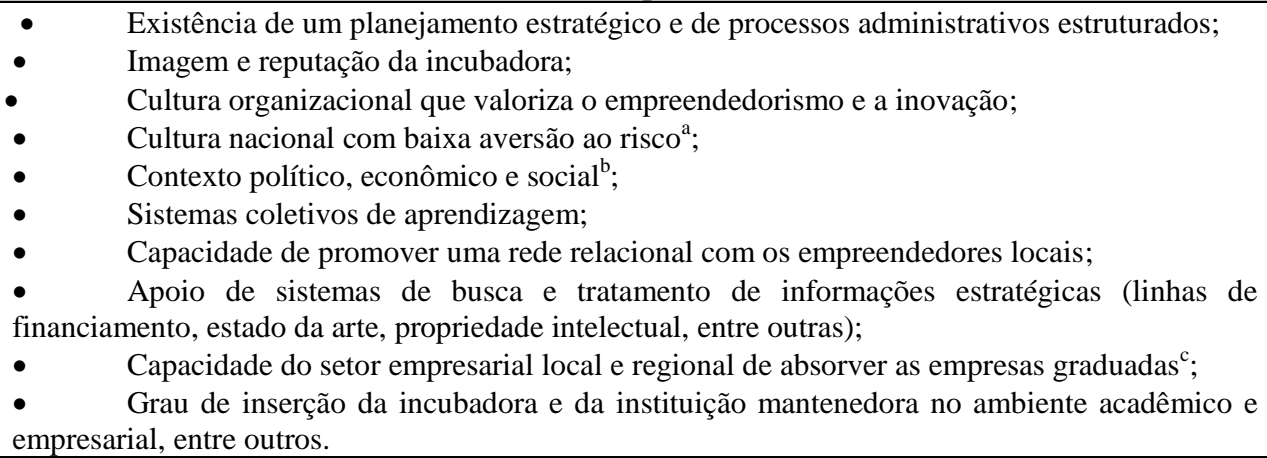 \\
\hline Intelectuais & $\begin{array}{l}\text { - Apoio, por meio de consultorias, dado por equipes internas da incubadora e da } \\
\text { mantenedora, ou por equipes externas (parceiros), aos incubados; } \\
\text { - } \\
\text { - } \\
\text { - } \\
\text { Competências específicas para captação de projetos; } \\
\text { - } \\
\text { - } \\
\text { - } \\
\text { Knompetências específicas em gestão de projetos e negócios; } \\
\text { outros. } \\
\text { Acesso a treinamentos específicas em gestão da propriedade intelectual; } \\
\text { Mentalidade empresarial dos pesquisadores envolvidos no processo de incubação; entre }\end{array}$ \\
\hline Físicos/Financeiros & $\begin{array}{l}\text { Localização geográfica da incubadora; } \\
\text { - } \\
\text { Acesso a laboratórios de parceiros (universidades, outros centros de pesquisa e empresas); } \\
\text { - } \\
\text { - } \\
\text { - } \\
\text { Acesso a recursos financeiros; } \\
\text { disponibilizados para o funcionamento da incubadora e para os empreendedores residentes. }\end{array}$ \\
\hline Relacionais & 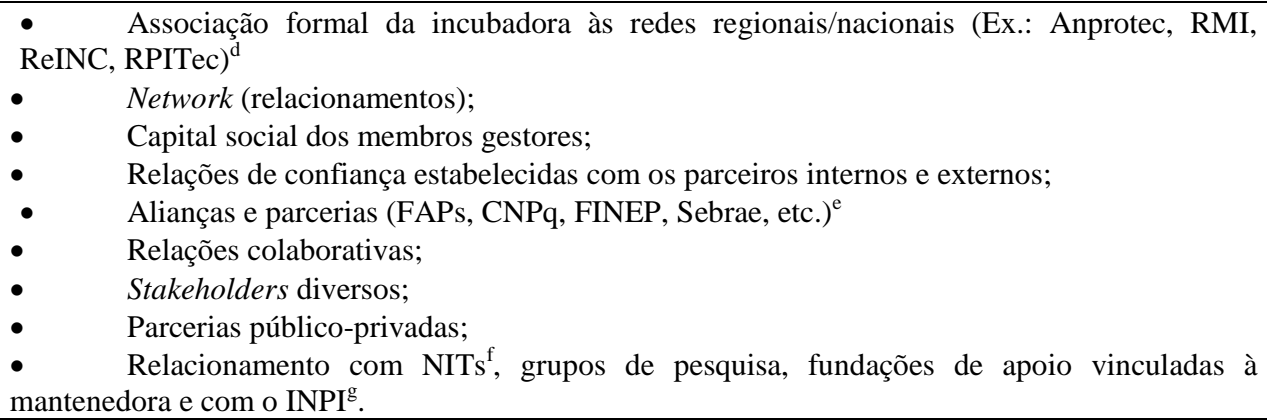 \\
\hline
\end{tabular}

Fonte: Elaborado pelas autoras com base em Clarysse, Wright, Lockettet et al. (2005) e de Brush, Green e Hart (2001)

Notas específicas: a, b e c: Recursos que assumem a condição de limite para a competição ex-ante; d:RMI - Rede Mineira de Inovação, ReINC - Rede de Incubadoras, Parques Tecnológicos e Pólos do Rio de Janeiro, RPITec: Rede Paulista de Incubadoras de Empresas de Base Tecnológica; e: FAPs - Fundações de Amparo à Pesquisa, CNPq - Conselho Nacional de Desenvolvimento Científico e Tecnológico, FINEP - Financiadora de Estudos e Projetos, Sebrae - Serviço Brasileiro de Apoio às Micro e Pequenas Empresas; f: NITs - Núcleos de Inovação Tecnológica; g: INPI - Instituto Nacional da Propriedade Industrial.

A relação existente entre a heterogeneidade e a imobilidade dos recursos com os atributos de valor, raridade, imitabilidade imperfeita e substitutibilidade para geração de vantagens competitivas sustentáveis, explicada por Barney (1991), ora aparecerá mais explícita na argumentação dos autores, ora estará implícita.

Essa análise não apenas especifica as condições teóricas sob as quais a vantagem competitiva pode existir, mas, também, aborda aspectos empíricos específicos que precisam ser endereçados a outros estudos, antes de poder ser amplamente entendida a relação entre um recurso particular e a vantagem competitiva sustentável. 
É importante considerar, ainda, que os recursos controlados por uma organização são complexos e interdependentes. Embora os gestores possuam hipóteses sobre quais recursos geram vantagens para as organizações, é difícil testá-las rigorosamente. Contudo, isso não invalida a tentativa de se buscar, em estudos teóricos e em exames empíricos, a identificação dos recursos que, quando desenvolvidos, ampliam e qualificam os resultados das organizações e geram vantagens competitivas.

Soetanto e Geenhuizen (2007) percebem o processo de incubação como uma ação recíproca de vários fatores externos e internos. Como fatores externos, os autores destacam os seguintes recursos: as redes de stakeholders (recursos relacionais), as condições econômicas urbanas e a cultura empreendedora (ambos, recursos organizacionais). Os fatores internos, por sua vez, referem-se às várias qualidades e estratégias das incubadoras, relacionadas à atração e ao gerenciamento de recursos para apoiar as empresas incubadas, incluindo procedimentos de seleção de candidatos, apoios específicos, capacidade de acompanhamento, treinamentos empresariais e avaliações das empresas graduadas, sendo que esses fatores encontram-se diluídos nos quatro grupamentos de recursos.

A interação das incubadoras com diferentes stakeholders, em oposição ao envolvimento apenas com a instituição mantenedora, significa possibilidades de acesso a uma maior variedade de recursos e de formação de redes, e, consequentemente, a uma maior capacidade de crescer e responder às heterogeneidades existentes entre as empresas incubadas (MONCK, PORTER, QUINTAS et al., 1988; DRUILHE e GARNSEY, 2004). Em termos do recurso de redes, Soetanto e Geenhuizen (2007) comprovaram, em seu estudo, que as incubadoras que seguem o modelo de rede, em interação com uma teia de organizações, e acessam recursos além dos da universidade (ou de outra instituição mantenedora), tendem a ser mais vigorosas e dinâmicas, o que qualifica o recurso de rede. Afinal, a diversidade de atores e a diversidade dos recursos compartilhados produzem novos conhecimentos para as incubadoras inseridas nessas redes.

Alguns estudos sobre IEBTs enfatizam que essas incubadoras devem desenvolver uma diversidade de recursos, contudo, à luz da RBV; sabe-se que as vantagens competitivas são construídas mais facilmente pelos recursos específicos. Nesse sentido, Phan, Siegel e Wright (2005) afirmam que as incubadoras conseguirão ampliar e qualificar seus resultados se elas desenvolverem recursos específicos (mais do que recursos não específicos), não disponíveis no mercado, ou seja, raros, além de desenvolverem a habilidade para aprender com a própria experiência e desenvolver novas competências. 
Baêta (1999) argumenta sobre a importância de as IEBTs, além do apoio usual das incubadoras tradicionais, oferecerem aos empreendedores residentes aconselhamento técnico, baseado em seu know-how tecnológico específico, já que possuem ligações com os centros de pesquisa e as universidades. Serra, Ribeiro Serra, Portugal Ferreira et al. (2011) corroboram esse argumento ao afirmarem que as incubadoras devem prover serviços de suporte com maior valor agregado, propiciando planejamento, acompanhamento dos empreendedores, ligação com outros empreendedores e com outras empresas. Incubadoras que disponibilizam serviços de suporte com valor agregado auxiliam no alcance de melhores resultados do que as incubadoras que oferecem serviços de suporte convencionais.

A relação candidato/vaga em cada processo de seleção de projetos e empresas em uma incubadora reflete a imagem dos benefícios esperados pelos empreendedores. De acordo com Serra, Ribeiro Serra, Portugal Ferreira et al. (2011), incubadoras que oferecem suporte adicional, além da infraestrutura, como, por exemplo, formação na área de gestão, acesso a recursos específicos, construção de parcerias, são mais atrativas.

Serra, Ribeiro Serra, Portugal Ferreira et al. (2011) argumentam, ainda, que os resultados alcançados pelas incubadoras estão vinculados ao quanto elas cumprem seu papel de facilitar a integração das empresas incubadas em redes relacionais, ao quanto conseguem fornecer serviços às empresas incubadas, além da tradicional disponibilização de infraestrutura, sendo que, nesse último caso, os efeitos resultam em um melhor desempenho candidato-vaga. A ideia é a de que as incubadoras distinguem-se umas das outras pela capacidade de integração das empresas em redes relacionais e pelos serviços agregados que são prestados. Além disso, Rezende (2015) constatou, em seu estudo, que a variedade de recursos de apoio disponibilizados aos empreendedores residentes pela instituição mantenedora da incubadora encoraja a criação de novos negócios e que a mantenedora percebe isso como uma dimensão estratégica.

O envolvimento de diversos stakeholders com as incubadoras implica no acesso potencial a diversos recursos, assim como influencia o acesso a redes de relacionamento mais ricas por sua diversidade, melhorando, assim, o desempenho das incubadoras (SERRA, RIBEIRO SERRA, PORTUGAL FERREIRA et al., 2011). Portanto, os resultados das incubadoras podem ser positivamente afetados por um conjunto adequado de parcerias e colaborações.

As políticas elaboradas para aumentar o crescimento das organizações, baseadas no conhecimento, enfrentam circunstâncias específicas que causam grande incerteza sobre a 
forma como a economia do conhecimento funciona e como as medidas políticas afetam essa economia (MORGAN, 1997; JIN e STOUGH, 1998; VAN GEENHUIZEN e NIJKAMP, 2006). Os diferentes atores envolvidos no processo de incubação incluem universidades e outras instituições superiores de ensino, institutos de pesquisa, empresas de consultoria, empresas fornecedoras, institutos de transferência de tecnologia, empresas de capital de risco, vários governos, entre outros. Esses atores usam seu próprio quadro de referência e perseguem diversos e, por vezes, conflitantes interesses, ao passo que alguns deles executam diferentes papéis em rápidas mudanças de rede.

A incerteza também decorre do quadro político local ou regional, que é multinível, ou seja, decisões políticas são tomadas em diferentes níveis espaciais, conduzindo, por exemplo, para decisões em níveis mais elevados, que influenciam as condições dos níveis inferiores. A situação de incerteza exige políticas adaptativas ou de aprendizagem, incluindo uma análise causal dos resultados das políticas assumidas (SOETANTO e GEENHUIZEN, 2007). Um contexto econômico, político e social favorável pode não representar um recurso diferenciado para incubadoras que estão localizadas na mesma região, mas, quando a competição é ampliada para localidades muito diferenciadas, esse se torna um recurso de valor para as incubadoras que o detêm.

Para crescerem e manterem-se competitivas, as regiões devem ser dotadas de um mercado de trabalho, cuja infraestrutura humana é de alta qualidade e diversidade, de serviços especializados e de uma variedade de fornecedores. Nesse cenário, as empresas atraem trabalhadores qualificados e criativos (GLAESER, E. L.; SHEINKMAN, J. A.; SHEIFER, A, 1995). Em termos do recurso localização, Soetanto e Geenhuizen (2007) assumiram, inicialmente, que as incubadoras em grandes áreas metropolitanas desfrutam dos benefícios de atrair pessoas de talento e um grande fluxo de novos empresários e que, por isso, desenvolvem-se com maior dinamismo; em contraste com incubadoras de empresas em zonas rurais e regiões periféricas, distantes das cidades metropolitanas. Contudo, eles constataram que as regiões não metropolitanas tendem a produzir incubadoras com crescimento relativamente rápido, enquanto que regiões metropolitanas tendem a produzir incubadoras com crescimento relativamente lento. Isso porque, em áreas metropolitanas, as vantagens de capital humano de alta qualidade e criatividade podem ser ofuscadas pelas desvantagens da aglomeração, como congestionamento rodoviário, os altos preços imobiliários, entre outros problemas, enquanto que as áreas rurais e periféricas não sofrem de tais desvantagens. 
Os autores constataram, ainda, que em áreas aglomeradas o processo de incubação pode trabalhar espontaneamente, reduzindo-se, assim, o papel das incubadoras (ou fazê-lo redundante) e tornando-as menos dinâmicas. Logo, o recurso físico localização geográfica da incubadora, que assume a condição de imobilidade e de limite ex-ante, quando superior, pode representar uma fonte de vantagem competitiva para as incubadoras.

As IEBTs necessitam de recursos humanos e condições estruturais e ambientais específicos (SERRA, RIBEIRO SERRA, PORTUGAL FERREIRA et al., 2011). Se a localização das IEBTs em grandes centros, sob alguns aspectos, pode ser um recurso desfavorável, sob outras perspectivas, pode ser um recurso bastante favorável. As IEBTs podem conseguir maior efetividade no cumprimento de sua função quando estão localizadas em grandes centros, nomeadamente pela diversidade de recursos disponíveis - como o talento e o conhecimento - e pelas relações construídas entre a academia, o governo e o setor empresarial. Podem, também, conseguir maior efetividade em cidades ou mesmo regiões que, embora não sejam grandes em extensão, sejam ricas em termos do conhecimento gerado, conforme explica Etzkowitz (2002).

Segundo Etzkowitz (2002), o processo de inovação depende fortemente da Triple Helix das interações entre a academia, o governo e as empresas e da hibridização dos papéis desses agentes. Rezende (2015) explica que as incubadoras são um dos mecanismos mais importantes para promover a articulação entre esses atores, o que torna valioso o recurso de rede, não apenas para a incubadora, mas para a própria rede. A academia não é apenas uma fonte geradora de conhecimento, mas atua como agente de estímulo e suporte de conhecimento para as empresas, por meio da realização de pesquisas e da transferência de tecnologia. As empresas e as organizações de apoio empresarial, por sua vez, não se limitam a produzir bens ou prestar serviços, mas preocupam-se com a formação e o compartilhamento de conhecimento. Os governos, sejam locais, regionais ou nacionais, por seu lado, fazem a gestão das políticas públicas de forma a direcionar os esforços inovativos, estimulando a transformação da ciência e da tecnologia em inovação, além de estimularem os empreendedores, atuarem como capitalistas de risco e exercerem seu papel tradicional de regulamentador.

Ainda em termos do recurso localização, Clarysse, Wright, Lockett et al. (2005) constataram que a dinâmica regional pode influenciar na eficácia das incubadoras. A presença de escritórios de transferência de tecnologia, a presença de investidores públicos e privados e a existência de uma rede de conhecimento local são os mecanismos principais, na opinião dos 
autores, para que uma região seja considerada de alta tecnologia. Esses recursos, por não estarem disponibilizados amplamente em todas as localidades que possuem incubadoras de empresas, tendem a gerar vantagens competitivas para as incubadoras que conseguem acessálos.

Hofstede (1991) resume as características da cultura nacional em algumas dimensões, que são: distância do poder, individualismo, masculinidade, orientação a longo prazo e aversão à incerteza. As empresas em países que enfrentam altos níveis de aversão à incerteza, geralmente, mostram resistência para entrar em novos caminhos e aversão aos riscos da inovação. Partindo dessa constatação, Soetanto e Geenhuizen (2007) propuseram que uma forte cultura empresarial (ou seja, a assunção de riscos) é favorável às incubadoras para que elas se tornem ativas em fornecer os melhores apoios às novas empresas que operam com tecnologias disruptivas e em mercados de risco, incluindo a inserção em novas redes. Logo, incubadoras localizadas em países que enfrentam níveis mais baixos de aversão às incertezas experimentariam um desenvolvimento mais dinâmico do que os países que enfrentam maiores níveis de aversão à incerteza. Eles constataram que a aversão ao risco parece influenciar somente um crescimento forte e, por isso, incubadoras localizadas em países que enfrentam baixa aversão ao risco tendem a ter um desempenho maior que aquelas que estão localizadas em países que enfrentam forte aversão ao risco. Contudo, uma baixa aversão ao risco também aparece nas regras que explicam um crescimento fraco das incubadoras estudadas por esses autores. Assim, os recursos cultura organizacional e cultura nacional podem influenciar positivamente as IEBTs, no entanto, esses recursos não determinam seu desempenho.

Soetanto e Geenhuizen (2007) abordam, ainda, a questão referente à natureza do apoio prestado pelas incubadoras. Segundo Hannon e Chaplin (2003), apoios convencionais são orientados para o fornecimento de ativos tangíveis (sala flexível, facilidades em laboratórios, apoio financeiro). No entanto, tem havido uma importante evolução sobre o tipo de apoio que eleva o seu valor, incluindo a conexão das empresas às várias redes e o fornecimento de novos métodos de aconselhamento empresarial, tais como os proporcionado pelas aceleradoras e os serviços de mentoria. Desse modo, incubadoras que empregam um modelo de valor agregado de apoio enfrentam um desenvolvimento mais dinâmico do que as incubadoras que se limitam a oferecer suporte convencional. Em termos da qualificação do agrupamento de recursos que são disponibilizados às empresas incubadas, Soetanto e Geenhuizen (2007) concluem que as incubadoras que fornecem suporte de valor agregado tendem a experimentar um crescimento relativamente forte, enquanto as que fornecem apenas suporte tradicional tendem a ter um 
desempenho fraco. Assim, os modelos de incubação que baseiam o apoio dado nas diferentes necessidades das empresas incubadas, em termos de redes de relacionamento e treinamentos de negócio, tendem a liderar um crescimento relativamente forte e serem mais competitivos.

Almeida, Borin, Álvarezet et al. (2011) dão destaque para o recurso de rede das IEBTs, por considerarem um recurso relevante para a busca da sua sustentabilidade. As incubadoras mobilizam-se em redes para identificar oportunidades em relação aos recursos escassos - tais como os financeiros, disponibilizados por instituições de apoio -, para ter acesso a eles e garantir sua sustentabilidade e seu desenvolvimento. O recurso de rede é importante também para o fortalecimento da interação das IEBTs com a rede nacional (Anprotec) e com as redes regionais. As redes regionais são vistas como um mecanismo de governança, por meio do qual as incubadoras desfrutam de um coerente sistema de apoio para a divulgação de informações e produção, disseminação e troca de conhecimentos entre os gestores de incubadoras.

As redes relacionais podem ser fundamentais para a eficácia das IEBTs, refletida no sucesso dos novos empreendimentos desenvolvidos dentro dessas incubadoras. Por meio das relações construídas, os empreendedores têm acesso a recursos de conhecimento, a outros também importantes e a contatos com o mercado, com as agências de financiamento, fornecedores e clientes (SERRA, RIBEIRO SERRA, PORTUGAL FERREIRA et al., 2011).

Os recursos de redes, com a participação de diferentes stakeholders, e o recurso de localização (em áreas não metropolitanas) tornaram-se a explicação mais contundente, para Soetano e Geenhuizen (2007), para o forte crescimento das incubadoras e para a criação de vantagens competitivas.

Em termos do recurso reputação e imagem da incubadora, Clarysse, Wright, Lockettet et. al. (2005) ressaltam que, normalmente, os pesquisadores que compõem as incubadoras e as instituições mantenedoras são especializados em um campo tecnológico e, por essa razão, podem ser conhecidos e respeitados nesse campo. Isso faz com que essas organizações não sejam apenas respeitadas no campo específico, mas, também, atraiam pesquisadores altamente talentosos de outras áreas, ampliando, portanto, seu reconhecimento perante as demais incubadoras. Reputação e imagem da IEBT significa, portanto, uma vantagem competitiva para a incubadora que conseguiu, ao longo do tempo, desenvolver know-how em um campo específico.

Para Tidd, Bessant e Pavitt (2008), os recursos intangíveis mais significativos são a reputação da empresa e o conhecimento dos empregados, o que pode estar relacionado à 
cultura empresarial. A cultura empresarial, definida como os valores e as crenças compartilhados pelos membros de uma empresa e os artefatos a ela associados, é essencial à aprendizagem corporativa. Esses recursos organizacionais e intelectuais assumem uma condição de imperfeita imitabilidade e geram vantagens competitivas para as IEBTs que souberem desenvolvê-los.

O recurso relações de confiança estabelecido entre os parceiros, segundo Almeida, Borin, Álvarez et al. (2011), quando não desenvolvido, prejudica a criação de vantagens competitivas pelas IEBTs. As disputas internas de poder e de acesso a recursos financeiros causa o risco de fragmentação do capital social dessas incubadoras. O recurso de rede é adequado para fortalecer as alianças interorganizacionais, reforçar os laços de confiança e o capital social. As relações colaborativas têm se destacado como um valor importante, que reforça a rede e contribui para o desenvolvimento e para a sustentabilidade das incubadoras e da própria rede.

Serra, Ribeiro Serra, Portugal Ferreira et al. (2011) assinalam que há um menor índice de mortalidade das empresas que passam pelo processo de incubação quando comparado com o índice de empresas que não passam. Isso fortalece o argumento de que é importante que as IEBTs desenvolvam, de forma mais vantajosa, os recursos organizacionais, físicos, intelectuais e relacionais, para ampliarem e qualificarem ainda mais seus resultados.

Os modelos de incubação não diferem apenas em termos da quantidade de recursos que irão demandar, mas, também, em termos do tipo de recursos necessários. Isso implica que é importante para essas organizações ter clareza sobre seus objetivos e especificar, com profundo conhecimento, os recursos e as atividades que são necessários para cumpri-los, pois a falta de clareza sobre tais objetivos resulta em recursos ou competências deficientes (CLARYSSE, WRIGHT, LOCKETT et al., 2005).

Sob a ótica da RBV, a deficiência de recursos, destinados ao desenvolvimento das empresas incubadas, ou a inabilidade para organizá-los, combiná-los e explorá-los, ou seja, para geri-los, constrange o desempenho das incubadoras. Portanto, a RBV constitui-se em uma apropriada lente para emoldurar a relação entre os recursos desenvolvidos pelas IEBTs e suas vantagens competitivas.

\section{CONSIDERAÇÕES FINAIS}

Sob a ótica da RBV, as IEBTs são compostas por um conjunto amplo e específico de recursos e de competências. Esse conjunto de recursos possui características únicas e não 
pode ser facilmente comprado e vendido no mercado. Os ativos que o compõem têm uma dimensão tácita forte, nascem da habilidade organizacional e do aprendizado coletivo e são socialmente complexos. É esse conjunto específico, conjugado com a forma como as IEBTs combinam e aplicam os recursos desse conjunto, que explica as vantagens competitivas sustentáveis dessas organizações.

A análise da gestão das IEBTs, na perspectiva da RBV, amplia o conhecimento sobre o porquê essas organizações apresentam resultados qualitativos e quantitativos diferenciados. As IEBTs acessam recursos diferentes e alguns, que apresentam características muito específicas e são desenvolvidos internamente, não podem ser acessados facilmente no mercado, o que caracteriza uma heterogeneidade nos recursos acessados. Além disso, alguns recursos, que asseguram vantagens competitivas duradouras a algumas incubadoras, são inacessíveis às outras que não conseguiram desenvolvê-los internamente. Logo, a vantagem competitiva das IEBTs é proveniente de uma base de recursos distintos e inacessíveis que elas desenvolvem.

Os recursos das IEBTs, que garantem vantagens competitivas, apresentam atributos que os qualificam como raros e valiosos. Contudo, confirmando o que explica a RBV, a sustentabilidade das vantagens competitivas geradas por esses recursos raros e valiosos está condicionada ao fato de esses recursos serem inimitáveis pelas demais organizações e serem insubstituíveis.

A habilidade das IEBTs obterem seus recursos depende de suas condições históricas, ou seja, da instituição à qual estão vinculadas, da região onde estão instaladas, das experiências construídas e do know-how tecnológico construído por ambas as instituições mantenedora e incubadora. O caminho percorrido por uma IEBT, nesse tempo e espaço, é singular e é responsável pelas decisões tomadas e pelas estratégias de desenvolvimento construídas.

Os recursos mais específicos, controlados pelas IEBTs, tais como as experiências construídas e o know-how tecnológico, são complexos e interdependentes, o que dificulta a compreensão do elo existente entre os recursos controlados e as vantagens competitivas sustentáveis desenvolvidas. Não sendo possível decifrar esse elo, esses recursos dificilmente serão copiados.

Outros recursos, tais como a sua cultura organizacional, a sua reputação e imagem e a qualidade das relações construídas com os parceiros são fenômenos sociais muito complexos. 
As diferentes IEBTs terão dificuldades de imitá-los. Por fim, os recursos de uma IEBT serão insubstituíveis quando eles não forem estrategicamente equivalentes aos das demais IEBTs.

Partindo do princípio de que as IEBTs são um conjunto amplo de recursos e competências, para que os recursos desenvolvidos sejam fontes de vantagens competitivas sustentáveis, eles precisam assumir as condições destacadas por Barney - valor, raridade, de difícil imitação e não serem estrategicamente equivalentes aos de outras IEBTs -, e, tão importante quanto esses atributos, é a capacidade dessas incubadoras de organizar, combinar e explorar da maneira mais eficaz e produtiva esses recursos.

Embora a RBV seja ainda difícil de ser operacionalizada, este estudo mostrou-se relevante para a análise dos recursos que representam vantagens competitivas para as IEBTs, possibilitando aos gestores dessas organizações construírem suas estratégias com base nesses recursos. Esta abordagem favorece o reconhecimento dos recursos já desenvolvidos, assim como contribui para a identificação dos novos recursos que precisam ser adequadamente apropriados ou desenvolvidos para a geração de vantagens competitivas sustentáveis.

Contudo, estudos empíricos precisam ser endereçados antes de poder ser amplamente entendida a relação entre um recurso particular e a vantagem competitiva sustentável das IEBTs. Além disso, o enfoque nos recursos acessados e desenvolvidos pelas incubadoras apontou para a necessidade de uma análise específica acerca das competências organizacionais para a gestão lidar com esses recursos de forma a assegurar a sustentabilidade das IEBTs.

\section{REFERÊNCIAS}

ALMEIDA, M. et al. Analysis of the Rio de Janeiro State Incubator Network (ReINC): characteristics and influence on the organization and sustainability of incubators. Interciencia, [s.l.], v. 36, n. 3, p. 171-177, mar. 2011. Disponível em:< https://dialnet.unirioja.es/servlet/articulo?codigo=3580805>. Acesso em: 11 ago. 2015.

ANPROTEC e MCTI (Brasil). Estudo, Análise e Proposições sobre as Incubadoras de Empresas no Brasil - relatório técnico / Associação Nacional de Entidades Promotoras de Empreendimentos Inovadores. Ministério da Ciência, Tecnologia e Inovação. Brasília: ANPROTEC, 2012. 24 p.

ANPROTEC (Brasil). Perguntas frequentes. Disponível em: <http://anprotec.org.br/site/menu/incubadoras-e-parques/perguntas-frequentes/> Acesso em: 08 set. 2015.

BAÊTA, A. M. C. O desafio da criação: uma análise das incubadoras de empresas de base tecnológica. Petrópolis, RJ: Vozes, 1999. 
BAÊTA, A. M. C.; BORGES, C. V.; TREMBLAY, D. G. Empreendedorismo Internacional nas incubadoras: perspectivas e desafios. Revista de Negócios, Blumenau, v. 10, n. 2, p. 76-87, abr./jun. 2005.

BARNEY, J. B. Strategic factor markets: Expectations, luck, and the theory of business strategy. Management Science, Catonsville, v. 32, p. 1512-1514, oct. 1986.

BARNEY, J. B. Firm Resources and Sustained Competitive Advantage. Journal of Management, Thousand Oaks, v. 17, n. 1, p. 99-120, mar. 1991.

BECKER, G. S. Human capital. New York: Columbia, 1964.

BORGES JR, C. V.; BERNASCONI, M; FILION L. J. La création des entreprises de haute technologie (EHT) Examende al documentation. Cahier de larecherche de la chaire d'entrepreneurship, Montreal, v. 11, 39 p., 2003.

BRUSH, C.G.; GREENE, P.G.; HART, M.M. From initial idea to unique advantage: The entrepreneurial challenge of constructing a resource base. Academy of Management Perspect, Briarcliff Manor, v. 15, n. 1, p. 64-78, feb. 2001.

CLARYSSE, B. et al. Spinning out new ventures: a typology of incubation strategies from European research institutions. Journal of Business Venturing, Amsterdã, v. 20, ed. 2, p. 183216, mar. 2005.

COHEN, W; LEVINTHAL, D. A. Absorptive capacity: a new perspective on learning and innovation. Administrative Science Quarterly, Thousand Oaks, v.35, n. 1, p.128-152, mar. 1990. Special Issue: Technology, Organizations, and Innovation.

COLLINS, D. J. How valuable are organizational capabilities? Strategic Management Journal, Nova Jersey, v. 15, p. 143-152, 1994.

DAFT, R. Organization theory and design. New York: West, 1983.

DIERICKX, I; COOL, K. Asset stock accumulation and sustainability of competitive advantage. Management Science, Catonsville, v.35, p. 1504-1511, dec. 1989.

DRUILHE, C; GARNSEY, E. Do academic spin-outs differ and does it matter? Journal of Technology Transfer, New York, v. 29, ed. 3, p. 269-285, aug. 2004.

ETZKOWITZ, H. Incubation of incubators: Innovation as a triple helix of university industrygovernment networks. Sci. Public Policy, ?]Bethesda, v. 29, ed. 2, p. 115-128, 2002.

ETZKOWITZ, H. Hélice Tríplice: Universidade-Indústria-Governo: Inovação em Movimento. Porto Alegre: EDIPUCRS, 2009.

ETZKOWITZ, H; MELLO, J; ALMEIDA, M. Towards 'Meta-Innovation' in Brazil: The evolution of the incubator and the emergence of a triple helix. Res. Policy, Amsterdã, v. 34, ed. 4, p. 411-424, may. 2005. 
GARCIA, F. P. et al. Reference Center for Business Incubation: a proposal for a new model of operation. In: CONFERÊNCIA DA NATIONAL BUSINESS INCUBATION ASSOCIATION (NBIA), 29., 2015, Denver, Estados Unidos. Anais... Disponível em:

<http://www.anprotec.org.br/Relata/artigoCernNBIA.pdf>. Acesso em: 23 set. 2015.

GLAESER, E. L.; SHEINKMAN, J. A.; SHEIFER, A. Economic growth in a cross-section of cities. Journal of Monetary Economics, Amsterdã, v. 36, p. 117-143, aug. 1995.

HALL, R. The strategic analysis of intangible resources. Strategic Management Journal, New Jersey, v. 13, ed. 2, p.135-144, feb. 1992.

HANNON, P. D.; CHAPLIN, P. Are incubators good for business? Understanding incubation practice-the challenges for policy. Environment and Planning C: Government and Policy, New Jersey, v. 21, n. 6, p. 861-881, dec. 2003.

HANSEN, G.;WERNERFELT, B. Determinants of firm performance: The relative importance of economic and organizational factors. Strategic Management Journal, New Jersey? ? 399-411, sep./oct.1989.

HOFER, C.; SCHENDEL, D. Strategy formulation: Analytical concepts. St. Paul, MN: West, 1978.

HOFSTEDE, G. Culture and Organizations: Software of the Mind. London: British Library, 1991.

JIN, D. J.; STOUGH, R. Learning and learning capability in the Fordist and post-Fordist age: an integrative framework. Environment and Planning A, Thousand Oaks, v. 30, n. 7, p. 1255-1278, jul.

LALKAKA, R. Business Incubator in developing countries: characteristics and performance. International Journal of Entrepreneurship and Innovation Management, Geneva, v. 3, n. 1/2, p. 31-55, nov. 2003.

LIPPMAN, S. A.; RUMELT, R. P. Uncertain imitability: an analysis of interfirm differences in efficiency under competition. Bell Journal of Economics, Nova Jersey, v. 13, n. 2, p. 418-438, 1982.

MINTZBERG, H.; AHLSTRAND, B.; LAMPEL, J. Safari de estratégia: um roteiro pela selva do planejamento estratégico. Porto Alegre: Bookman, 2000.

MONCK, C. S. P. et al. Science Parks and the Growth of High Technology Firms. London: Croom Helm, 1988.

MORGAN, K. The learning region: institutions, innovation and regional renewal. Regional Studies, Routledge, v. 31, ed. 5, p. 491-503, 1997.

MUELLER, D. Profits in the Long Run. Cambridge: Cambridge University Press, 1986. 
NATIONAL BUSINESS INCUBATION ASSOCIATION-NBIA (Estados Unidos). What is business incubation? Disponível em: <http://www.nbia.org/resources/business-incubation-faq >. Acesso em: 08 set. 2015.

NELSON, R. R.; WINTER, S. An Evolutionary Theory of Economic Change. Cambridge: Harvard University Press, 1982.

PASTRE, F.; VEDOVATTO, A. D. Gestão Financeira e Sustentabilidade na Incubadora Tecnológica da Unochapecó - INCTECh: adequação à prática chave na metodologia CERNE 1. In: SEMINÁRIO NACIONAL DE PARQUES TECNOLÓGICOS E INCUBADORAS DE EMPRESAS, 24., 2014, Belém. Anais eletrônicos... Belém: Anprotec, 2014. Disponível em: <

http://www.anprotec.org.br/Relata/ArtigosCompletos/ID\%2044.pdf>. Acesso em: 13 ago. 2015.

PENROSE, E.T. The Theory of the Growth of the Firm. New York: Wiley, 1959.

PETERAF, M. A. The cornerstones of competitive advantage: a resource based view. Strategic Management Journal, Nova Jersey, v.14, p. 179-191, mar. 1993.

PHAN, P. H.; SIEGEL, D. S.; WRIGHT, M. Science parks and incubators: observations, synthesis and future research. Journal of Business Venturing, Amsterdam,v. 20, ed. 2, p. 165-182, mar. 2005.

PORTER, M. E. The contributions of industrial organization to strategic management. Academy of Management Review, Briarcliff Manor, v. 6, p. 609-620, oct. 1981.

PORTER, M. E. Estratégia Competitiva: técnicas para análise de indústrias e da concorrência. Rio de Janeiro: Campus, 1986.

PORTER, M. E. Vantagem competitiva: criando e sustentando um desempenho superior. Rio de Janeiro: Campus/Elsevier, 1989.

PRAHALAD, C. K.; HAMEL, G. The core competence of the corporation. Harvard Business Review, Cambridge, v. 68, ed. 3, p. 79-91, may-jun. 1990.

RAMOS-RODRÍGUEZ, A. R.; RUÍZ-NAVARRO, J. Changes in the intelectual structure of strategic management research: a bibliometric study of the strategic management journal, $1980-2000$. Strategic Management Journal, Nova Jersey, v. 25, ed. 10, p. 981-1004, oct. 2004.

REZENDE, J. F.D. de. Análise do cenário de incubadoras, parques tecnológicos e redes de incubação no Estado da Flórida (EUA). In: SEMINÁRIO DE PESQUISA DO CCSA, 20., 2015, Natal. Anais... Natal. Disponível em: < http://seminario.ccsa.ufrn.br/anais>. Acesso em 13 ago. 2015.

RUMELT, R. P. Towards a strategic theory of the firm. In Competitive Strategic Management, Nova Jersey, Lamb RB (ed). Prentice-Hall: Englewood Cliffs, NJ; p. 556-570, 1984.

RUMELT, R. P. How much does industry matter? Strategic Management Journal, New Jersey. v. 12, ed. 3, p. 167-185, mar. 1991.

REAd | Porto Alegre - Edição 85 - № 3 - Setembro / Dezembro 2016 - p. 462 - 493 
SCHERER, F. M. Industrial market structure and economic performance. 2. ed. Boston: Houghton-Mifflin, 1980.

SCHMALENSEE, R. Do markets differ much? The American Economic Review, Pittsburgh, v. 75, n. 3, p. 341-351, jun.1985.

SERRA, B.; RIBEIRO SERRA, F.; PORTUGAL FERREIRA, M.; GONÇALVES FIATES, G. Fatores fundamentais para o desempenho de incubadoras de base tecnológica. RAl - Revista de Administração e Inovação, São Paulo, v. 8, n. 1, p. 221-247, enero-marzo 2011. Disponível em: <http://www.revistarai.org/rai/article/view/527>. Acesso em: 12 ago 2015.

SILVA, S. A. A relevância das incubadoras de empresas no mundo contemporâneo. Ponto-evírgula (PUCSP), São Paulo, v. 6, p. 235-251, 2010a.

SILVA, S. A. O papel social das incubadoras de empresas de Belo Horizonte: um estudo de caso. Dissertação (Mestrado) - Programa de Estudos Pós-Graduados em Ciências Sociais, Pontifícia Universidade Católica de São Paulo, São Paulo, 2010.

SOETANTO, D.; Van GEENHUIZEN, M. Technology incubators and knowledge networks: a rough set approach in comparative project analysis. Environment and Planning B: Planning and Design, Thousand Oaks, v.34, n. 6, p. 1011-1029, dec. 2007.

STINCHOCOMBE, A. L. Social structure and organizations. In J. G. March (Ed.), Handbook of Organizations. Chicago: Rand-McNally, 1965. p. 142-193.

TEECE, D. J. Towards an economic theory of the multiproduct firm. Journal of Economic Behavior and Organization, Amsterdã, v. 3, ed. 1, p. 39-63, mar. 1982.

TIDD, J.; BESSANT, J.; PAVITT, K. Gestão da Inovação. Porto Alegre, RS: Bookman, 2008.

TOMER, J. F. Organizational capital: The path to higher productivity and well-being. New York: Praeger, 1987.

VAN GEENHUIZEN, M.; NIJKAMP, P. Learning regions in an evolutionary context: policymaking, for high technology firms. International Journal of Entrepreneurship and Innovation Management, Olney, v. 6, n. 3, p. 264-282, 2006.

ZOUAIN, D. M.; SILVEIRA, A. C. Aspectos estratégicos do modelo de gestão em incubadoras de empresas de base tecnológica. Cad. EBAPE. BR [online], v. 4, n. 3, p. 01-14, 2006. Disponível em: < http://bibliotecadigital.fgv.br/ojs/index.php/cadernosebape/article/view/4985>. Acesso em: 28 jun. 2015.

WERNERFELT, B.A resource-based view of the firm. Strategic Management Journal, New York, v. 5, n. 2, p. 171-180, apr./jun. 1984.

WERNERFELT, B.; MONTGOMERY, C. A. Tobin's $q$ and the importance of focus in firm performance. American Economic Review, Washington, v. 78, n. 1, p. 246-250, mar. 1988. 
WILLIAMSON, O. E. Markets and hierarchies. New York: Free Press, 1975.

REAd | Porto Alegre - Edição 85 - № 3 - Setembro / Dezembro 2016 - p. 462 - 493 